\title{
Modeling and Simulation of an Induction Drive with Application to a Small Wind Turbine Generator
}

\author{
Levente TAMAS1 and Zoltan SZEKELY2 \\ ${ }^{1}$ Technical University of Cluj-Napoca, Romania \\ 2Purdue University Calumet, USA
}

\section{Introduction}

In recent years the rapid development of digital signal processors (DSP) based systems and the decreasing cost of power electronics allowed the complex models and control algorithms of AC machines to become popular for a large range of applications including the ones for renewable energies. Among renewable energies the solution of utilizing induction generators for wind energy conversion systems is now in a growing trend. Currently, a wide spread control concept is that of a variable speed rotor with pitch regulation, and this concept is combined with both direct drive and geared drive trains the latter dominating the wind market (Tamas \& Szekely, 2008).

A valid choice for operation at variable speed may be the use of induction machine. An induction motor can operate as a generator in super synchronous speed raised by an overhauling type of load, or by lowering the inverter frequency below the machine speed, when there is a converter-fed machine drive. Continuous regenerative operation of a drive is possible if the load machine is a source of power, such as in a wind generation system (Tamas \& Szekely, 2008).

In this paper the model of the induction machine is written in terms of fluxes as state variables. This model is then used to design an Extended Kalman Filter (EKF) based estimator that can provide the correct feedback signals for the vector control (VC) of a wind energy conversion system.

Also three other observers are shown with good simulation results, one based on stator voltages and stator currents (Us-Is), one based on stator voltages and rotor speed (Us- $\omega$ ) and one based on stator currents and rotor speed (Is - $\omega$ ). A neural network based speed estimator as a forth type of estimator is developed which can be used for sensorless vector control of the induction drive or as a part of a sensor fusion based feedback signal estimator combined with one of the above mentioned estimators.

Finally, a real-time simulation setup is presented using dSpace CLP1104 embedded system (Tamas \& Szekely, 2008) together with the possible further research steps in this project. 


\section{Wind Turbine System Model}

Fig. 1 shows a basic wind turbine system that converts the wind energy into mechanical energy which at its turn is used by an electric machine to generate power. The basic configuration consists of the wind turbine blades, the drive train, the induction generator and the AC-AC converter (not shown in Fig. 1 to connect the system to the grid).

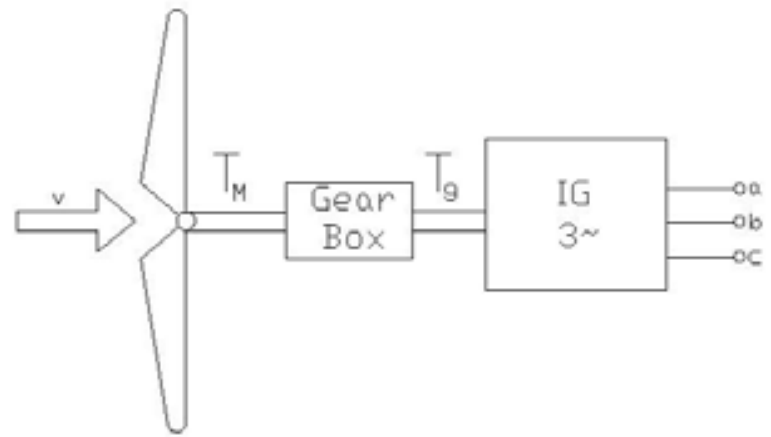

Fig. 1. Basic wind turbine system model

\subsection{Wind turbine model}

The models of wind turbines take into account several characteristics such as the size, blade radius, nominal power, shafts stiffness, losses, gear box ratio, etc. The mechanical power produced by the wind turbine is:

$$
\mathrm{P}_{\mathrm{M}}=\frac{1}{2} \rho_{\text {air }} \mathrm{c}_{\mathrm{p}} \pi \mathrm{R}^{2} v^{3}
$$

where $\rho$ is the air density, $\pi \mathrm{R}^{2}$ is the turbine swept area, $v$ is the speed of the wind, and $\operatorname{cp}(\lambda)$ is the power efficiency coefficient of the wind turbine which depends on the tip-speed ratio, $\lambda$. This is defined as:

$$
\lambda=\frac{{ }^{\omega_{M}} \mathrm{M}^{\mathrm{R}}}{v}
$$

where, $\omega_{M}=\frac{d \theta}{d t}$ is the angular speed of the turbine blades, and $R$ is the length of the turbine blade.

There is an optimal value of the tip speed ratio, $\lambda$ opt, which allows a maximum capture of power from the wind. This value is found from the typical characteristic of the wind turbine power coefficient $c p=f(\lambda)$ provided by the manufacturers.

When the wind turbine is operating with $\lambda$ opt, the nonlinear power expression from (1) may be recalculated as:

$$
\mathrm{P}_{\mathrm{Mopt}}=\mathrm{c}_{\mathrm{opt}} \omega_{\mathrm{M}}^{3}
$$

and the corresponding mechanical torque produced by the blades is: 


$$
\mathrm{T}_{\mathrm{M} \text { opt }}=\mathrm{c}_{\mathrm{opt}} \omega_{\mathrm{M}}^{2}
$$

where, Copt is a constant which depends on the turbine characteristics and air density (Kelemen \& Imecs, 1991).

\subsection{Drive train model}

The drive train dynamics consists of the dynamics of the wind turbine rotor, low-speed shaft, gear box, high-speed shaft, and the induction generator Fig. 2 shows the basic diagram of the drive train that was used for the derivation of the mathematical model (Kelemen \& Imecs, 1991).

Thus, for the wind turbine rotor the following torques equation can be written:

$$
\mathrm{J}_{\mathrm{M}} \frac{\mathrm{d}^{2}{ }^{2} \mathrm{M}}{\mathrm{dt}^{2}}+\mathrm{T}_{\mathrm{G}}=\mathrm{T}_{\mathrm{M}}(\mathrm{t})
$$

where, $T_{G}=K_{1} \Delta \theta_{K 1}$ is the reaction torque exerted by the flexible low-speed shaft on the rotor of the wind turbine.

Similarly, for the rotor of the induction generator the following torques equation is valid:

$$
\mathrm{J}_{\mathrm{g}} \frac{\mathrm{d}^{2} \theta_{\mathrm{r}}}{\mathrm{dt}^{2}}-\mathrm{T}_{\mathrm{g}}+\mathrm{T}_{\mathrm{e}}=0
$$

where $\mathrm{T}_{\mathrm{g}}=\mathrm{K}_{2} \Delta \theta_{\mathrm{K} 2}$ is the reaction torque exerted by the high-speed shaft on the induction generator rotor, and $T_{e}$ is the electromagnetic torque of the induction machine in generator operation mode.

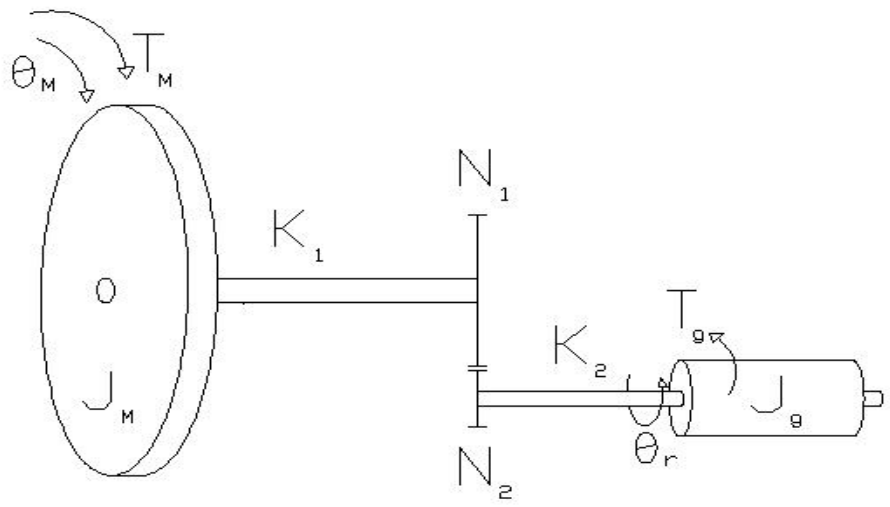

Fig. 2. Drive train model

The reference values for the above mechanical parameters where reported in (Scutaru \& Apostoaia, 2004). 


\subsection{Induction generator model}

In this paper, the model of the induction generator is derived using as state parameters the stator and rotor flux d-q axis components and the angular speed of the induction generator. The model is a fifth order dynamic model. It is also assumed that the induction drive is a standalone generator so that the excitation capacitor and load impedance are added to the model.

The mathematical model of the induction machine having fluxes as state variables, and written in terms of inductances, is represented by the set of (7) - (11):

$$
\begin{gathered}
\frac{\mathrm{d} \psi_{\mathrm{sd}}}{\mathrm{dt}}=-\frac{\mathrm{R}_{\mathrm{s}}}{\sigma \mathrm{L}_{\mathrm{s}}}\left(\psi_{\mathrm{sd}}-\frac{\mathrm{L}_{\mathrm{m}}}{\mathrm{L}_{\mathrm{r}}} \psi_{\mathrm{rd}}\right)+\omega_{\lambda} \psi_{\mathrm{sq}}+\mathrm{u}_{\mathrm{sd}} \\
\frac{\mathrm{d} \psi_{\mathrm{sq}}}{\mathrm{dt}}=-\frac{\mathrm{R}_{\mathrm{s}}}{\sigma \mathrm{L}_{\mathrm{s}}}\left(\psi_{\mathrm{sq}}-\frac{\mathrm{L}_{\mathrm{m}}}{\left.\mathrm{L}_{\mathrm{r}} \omega_{\mathrm{rq}}\right)-\omega_{\lambda} \psi_{\mathrm{sd}}+\mathrm{u}_{\mathrm{sq}}}\right. \\
\frac{\mathrm{d} \psi_{\mathrm{rd}}}{\mathrm{dt}}=-\frac{\mathrm{R}_{\mathrm{r}}}{\sigma \mathrm{L}_{\mathrm{s}}}\left(\psi_{\mathrm{sd}}-\frac{\mathrm{L}_{\mathrm{m}}}{\mathrm{L}_{\mathrm{r}}} \psi_{\mathrm{sd}}\right)+\left(\omega_{\lambda}-\omega\right)_{\mathrm{rq}}+\mathrm{u}_{\mathrm{rd}} \\
\frac{\mathrm{d} \psi_{\mathrm{rq}}}{\mathrm{dt}}=-\frac{\mathrm{R}_{\mathrm{r}}}{\sigma \mathrm{L}_{\mathrm{r}}}\left(\psi_{\mathrm{rq}}-\frac{\mathrm{L}_{\mathrm{m}}}{\mathrm{L}_{\mathrm{s}}} \psi_{\mathrm{sq}}\right)-\left(\omega_{\lambda}-\omega\right) \psi_{\mathrm{rd}}+\mathrm{u}_{\mathrm{rq}} \\
\frac{\mathrm{d} \omega}{\mathrm{dt}}=\frac{3}{2} \frac{\mathrm{z}_{\mathrm{p}}^{2}}{\mathrm{~J}} \frac{\mathrm{L}_{\mathrm{m}}}{\mathrm{L}_{\mathrm{s}}}\left(\psi_{\mathrm{sq}} \mathrm{i}_{\mathrm{rd}}-\psi_{\mathrm{sd}} \mathrm{i}_{\mathrm{rq}}\right)-\frac{\mathrm{z}_{\mathrm{p}}}{\mathrm{J}} \mathrm{T}_{\mathrm{g}}
\end{gathered}
$$

An induction generator may be self-excited by providing the magnetizing reactive power by a capacitor bank (Scutaru \& Apostoaia, 2004). In Fig. 3 a stand-alone induction generator under an R-L resistive-inductive load is shown.

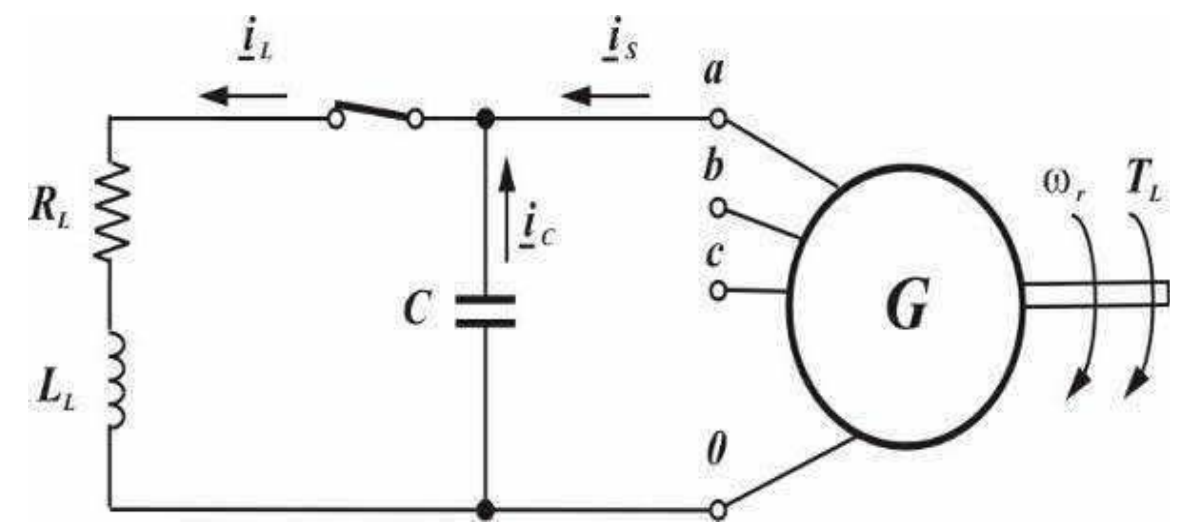

Fig. 3. Single-phase R-L load circuit 
The stator voltages usd and usq are computed as state variables in the generator's load impedance model as follows:

$$
\begin{gathered}
\frac{\mathrm{du}_{\mathrm{sd}}}{\mathrm{dt}}=-\frac{1}{\mathrm{C}} \mathrm{i}_{\mathrm{sd}}+\frac{1}{\mathrm{C}} \mathrm{i}_{\mathrm{Ld}} \\
\frac{\mathrm{du_{ \textrm {sq } }}}{\mathrm{dt}}=-\frac{1}{\mathrm{C}} \mathrm{i}_{\mathrm{sq}}+\frac{1}{\mathrm{C}} \mathrm{i}_{\mathrm{Lq}} \\
\frac{\mathrm{di}_{\mathrm{Ld}}}{\mathrm{dt}}=\frac{1}{\mathrm{~L}_{\mathrm{L}}}\left(\mathrm{u}_{\mathrm{sd}}-\mathrm{R}_{\mathrm{L}} \mathrm{i}_{\mathrm{Ld}}\right)+\omega_{\lambda} \mathrm{i}_{\mathrm{Lq}} \\
\frac{\mathrm{di}_{\mathrm{Lq}}}{\mathrm{dt}}=\frac{1}{\mathrm{~L}_{\mathrm{L}}}\left(\mathrm{u}_{\mathrm{sq}}-\mathrm{R}_{\mathrm{L}} \mathrm{i}_{\mathrm{Lq}}\right)-\omega_{\lambda} \mathrm{i}_{\mathrm{Ld}}
\end{gathered}
$$

The electromagnetic torque expression can be written in terms of the state variables:

$$
\mathrm{T}_{\mathrm{e}}=\frac{3}{2} \mathrm{z}_{\mathrm{p}} \frac{\mathrm{L}_{\mathrm{m}}}{\sigma \mathrm{L}_{\mathrm{s}} \mathrm{L}_{\mathrm{r}}}\left(\psi_{\mathrm{sq}} \psi_{\mathrm{rd}}-\psi_{\mathrm{sd}} \psi_{\mathrm{rq}}\right)
$$

Fig. 4 shows the complete Simulink model of the wind conversion system described by (1)(16). 

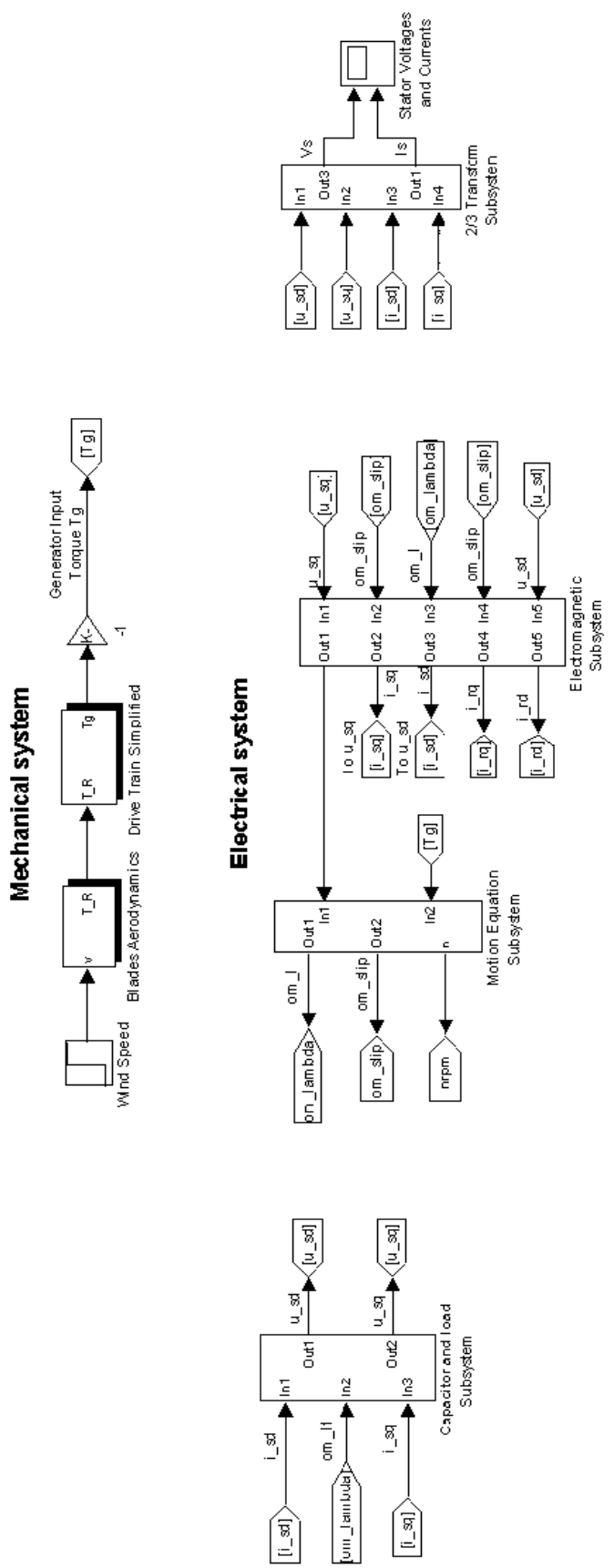

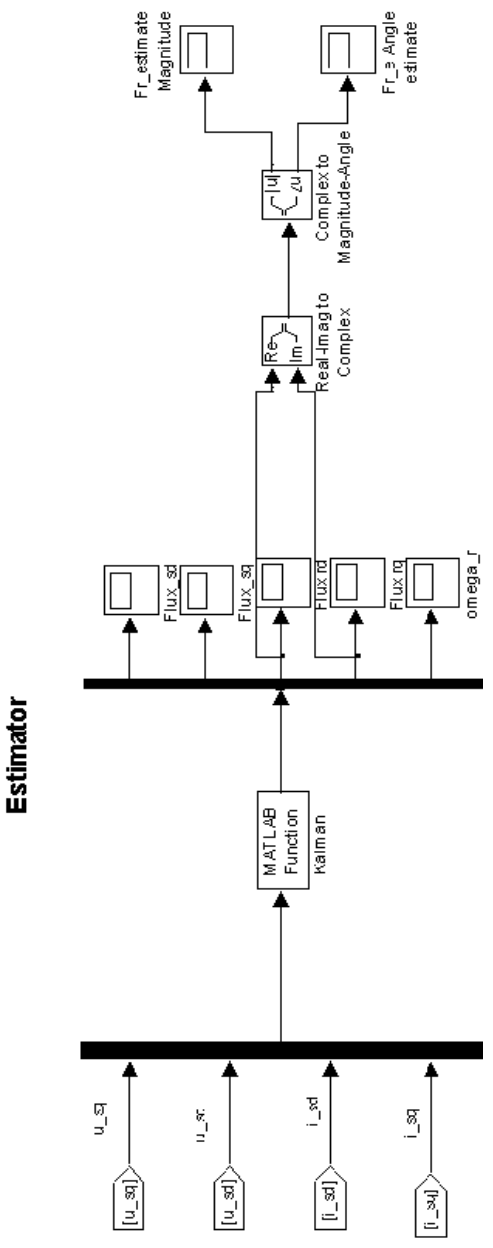

Fig. 4. Simulink block diagram of the dynamic system with EKF estimator 


\subsection{State space model of the induction generator}

The state space equations (7)-(11) of the induction machine can be rewritten in matrix form as in (17):

$$
\begin{gathered}
\frac{\mathrm{dx}}{\mathrm{dt}}=\mathrm{A} \cdot \mathrm{x}+\mathrm{B} \cdot \mathrm{u} \\
\mathrm{y}=\mathrm{C} \cdot \mathrm{x}
\end{gathered}
$$

In (17) the state variables input and output vectors are as follows:

$$
\begin{gathered}
\mathrm{x}=\left[\begin{array}{lllll}
\psi_{\text {sd }} & \psi_{\text {sq }} & \psi_{\text {rd }} & \psi_{\text {rq }} & \omega
\end{array}\right]^{\mathrm{T}} \\
\mathrm{u}=\left[\begin{array}{lllll}
\mathrm{u}_{\mathrm{sd}} & \mathrm{u}_{\mathrm{sq}} & 0 & 0 & 0
\end{array}\right]^{\mathrm{T}} \\
\mathrm{y}=\left[\begin{array}{lllll}
\mathrm{i}_{\mathrm{sd}} & \mathrm{i}_{\mathrm{sq}} & \mathrm{i}_{\mathrm{rd}} & \mathrm{i}_{\text {rq }} & 0
\end{array}\right]^{\mathrm{T}}
\end{gathered}
$$

where, urd and urq are considered zero because of the squirrel cage type of the induction generator.

The system matrix $A$, the input matrix $B$ and the output matrix $C$ are:

$$
\begin{aligned}
& A=\left[\begin{array}{ccccc}
-\frac{R_{S}}{\sigma_{S}} & \omega_{\lambda} & \frac{R_{S} L_{m}}{\sigma_{S} L_{r}} & 0 & 0 \\
-\omega_{\lambda} & -\frac{R_{S}}{\sigma_{S}} & 0 & \frac{R_{S} L_{m}}{\sigma_{S} L_{r}} & 0 \\
\frac{R_{r} L_{m}}{\sigma_{S} L_{r}} & 0 & -\frac{R_{r}}{\sigma_{r}} & \omega_{\lambda}-\omega & 0 \\
0 & \frac{R_{r} L_{m}}{\sigma_{S} L_{r}} & \omega-\omega_{\lambda} & -\frac{R_{r}}{\sigma_{r}} & 0 \\
0 & 0 & 0 & 0 & 0
\end{array}\right] \\
& \mathrm{B}=\left[\begin{array}{lllll}
1 & 0 & 0 & 0 & 0 \\
0 & 1 & 0 & 0 & 0 \\
0 & 0 & 0 & 0 & 0 \\
0 & 0 & 0 & 0 & 0 \\
0 & 0 & 0 & 0 & 0
\end{array}\right] \\
& \mathrm{C}=\left[\begin{array}{ccccc}
\frac{1}{\sigma \mathrm{L}_{\mathrm{s}}} & 0 & -\frac{\mathrm{L}_{\mathrm{m}}}{\sigma \mathrm{L}_{\mathrm{s}} \mathrm{L}_{\mathrm{r}}} & 0 & 0 \\
0 & \frac{1}{\sigma \mathrm{L}_{\mathrm{S}}} & 0 & -\frac{\mathrm{L}_{\mathrm{m}}}{\sigma \mathrm{L}_{\mathrm{S}} \mathrm{L}_{\mathrm{r}}} & 0 \\
-\frac{\mathrm{L}_{\mathrm{m}}}{\sigma \mathrm{L}_{\mathrm{s}} \mathrm{L}_{\mathrm{r}}} & 0 & \frac{1}{\sigma \mathrm{L}_{\mathrm{r}}} & 0 & 0 \\
0 & -\frac{\mathrm{L}_{\mathrm{m}}}{\sigma \mathrm{L}_{\mathrm{s}} \mathrm{L}_{\mathrm{r}}} & 0 & \frac{1}{\sigma \mathrm{L}_{\mathrm{r}}} & 0 \\
0 & 0 & 0 & 0 & 0
\end{array}\right]
\end{aligned}
$$

The numerical data for the induction generator parameters found in (21) and (23) can be found in the Appendix. 
A successful build-up process, is predicted as in Fig. 5 and in Fig. 6 shows for a slip frequency of $-0.5 \omega$, an excitation capacitance value of $700 \mu \mathrm{F}$, and a resistive inductive load with $R=7 \mathrm{k} \Omega$ and $L=10 \mathrm{H}$. The simulation was carried out for a speed of 400 , see Fig. 7 .

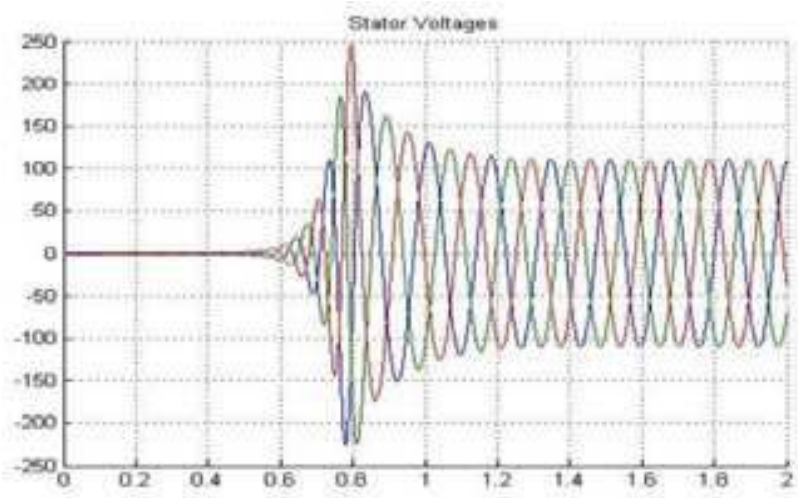

Fig. 5. Stator voltages during a start up of the loaded induction generator

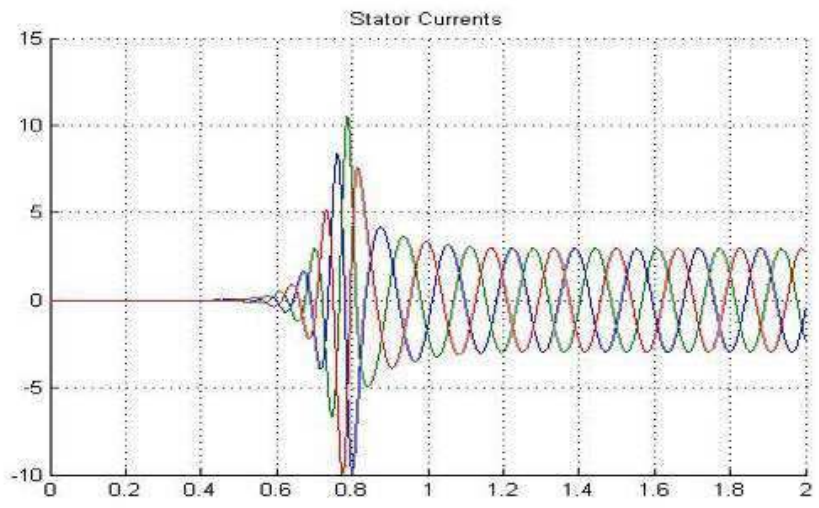

Fig. 6. Stator currents during a start up of the loaded induction generator

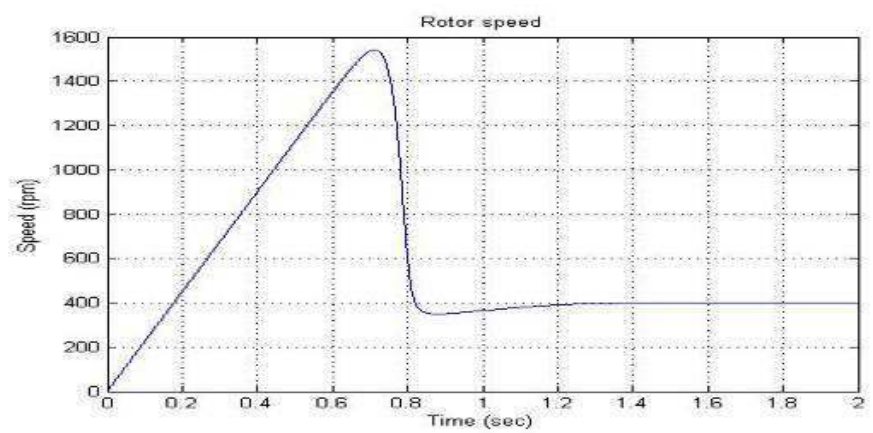

Fig. 7. Rotor speed of the induction generator during start up 


\section{State observers}

\subsection{Extended Kalman filter estimator (EKF)}

The filtering problem involved in this paper is to find the best estimate of the state vector $\mathrm{xk}$ of the induction machine which evolves according to the discrete- time nonlinear state transition equation (Kalman, 1960):

$$
\mathrm{x}_{\mathrm{k}}=\mathrm{f}\left(\mathrm{x}_{\mathrm{k}-1}, \mathrm{u}_{\mathrm{k}-1}\right)+\mathrm{w}_{\mathrm{k}-1}
$$

where, $f(\bullet, \bullet)$ is the machine dynamics, $x_{k-1}$ is the state observation of the machine at sampling time $k-1, u_{k-1}$ is the known input at time step $k-1$ and $w_{k-1}$ is the system noise, which is white noise with a Gaussian distribution with mean zero and covariance $Q$. Also we admit that we possess a set of noisy measurements, noted as $z$ :

$$
\mathrm{z}_{\mathrm{k}}=\mathrm{h}\left(\mathrm{x}_{\mathrm{k}}\right)+\mathrm{v}_{\mathrm{k}}
$$

where, $h(\bullet)$ is a function of the state parameters and $v_{k}$ is the measurement noise, with a Gaussian distribution with mean zero and covariance $R$.

First the estimated states are calculated (prediction step) then using the measurements these states are updated in function of the Kalman gain $(\mathrm{K})$.

The estimation (prediction) equations are:

$$
\begin{gathered}
\hat{\mathrm{x}}_{\mathrm{k}}^{-}=\mathrm{f}\left(\hat{\mathrm{x}}_{\mathrm{k}-1}^{+}, \hat{\mathrm{u}}_{\mathrm{k}-1}\right)+\hat{\mathrm{w}}_{\mathrm{k}-1} \\
\mathrm{P}_{\mathrm{k}}^{-}=\mathrm{A}_{\mathrm{k}} \mathrm{P}_{\mathrm{k}-1} \mathrm{~A}_{\mathrm{k}}^{\mathrm{T}}+\mathrm{B}_{\mathrm{k}} \mathrm{U}_{\mathrm{k}-1} \mathrm{~B}_{\mathrm{k}}^{\mathrm{T}}+\mathrm{Q}_{\mathrm{k}-1}
\end{gathered}
$$

where, $\hat{\mathrm{x}}_{\mathrm{k}-1}^{+}$the previous state estimate, with covariance matrix $\mathrm{P}_{\mathrm{k}-1}, \hat{\mathrm{u}}_{\mathrm{k}-1}$ is the control input with covariance matrix $\mathrm{U}_{\mathrm{k}-1}, f(\cdot, \cdot)$ is the system dynamics function and $\hat{\mathrm{w}}_{\mathrm{k}-1}$ is the system noise with covariance $Q_{k-1}$.

The update equations following a measurement:

$$
\begin{gathered}
\hat{\mathrm{x}}_{\mathrm{k}}^{+}=\hat{\mathrm{x}}_{\mathrm{k}}^{-}+\mathrm{K}_{\mathrm{k}}\left(\mathrm{z}_{\mathrm{k}}-\mathrm{h}\left(\hat{\mathrm{x}}_{\mathrm{k}}^{-}\right)\right) \\
\mathrm{P}_{\mathrm{K}}^{+}=\left(\mathrm{I}-\mathrm{K}_{\mathrm{k}} \mathrm{H}_{\mathrm{k}}\right) \mathrm{P}_{\mathrm{k}}^{-} \\
\mathrm{K}_{\mathrm{k}}=\mathrm{P}_{\mathrm{k}}^{-} \mathrm{H}_{\mathrm{k}}^{\mathrm{T}}\left(\mathrm{H}_{\mathrm{k}} \mathrm{P}_{\mathrm{k}}^{-} \mathrm{H}_{\mathrm{k}}^{\mathrm{T}}+\mathrm{R}_{\mathrm{k}}\right)^{-1}
\end{gathered}
$$

where, $K_{k}$ is the Kalman gain, $z_{k}$ is the measurement at time step $k, h(\bullet)$ is a function of the state vector, $H$ is the observation matrix, $R_{k}$ is the covariance of the measurement noise $v_{k}$.

At the first step of the algorithm the values of $x$ and $P$ are initialized with the prior knowledge about the system. It is not a trivial task to tune the values of the covariance $R$ and $Q$. These values influence the performance of the filter although there is no direct 
method of choosing them in real time applications and it is often the case that they are selected in a trial and error method.

The Extended Kalman Filter estimator is implemented using Matlab function. The inputs for the function are the stator voltages, and the stator currents are the noise measurements.

Fig. 8 shows the estimated state variables, the stator and rotor d-q axis fluxes. Fig. 9 shows the rotor flux magnitude and the rotor flux vector angle can be seen from Fig. 10.
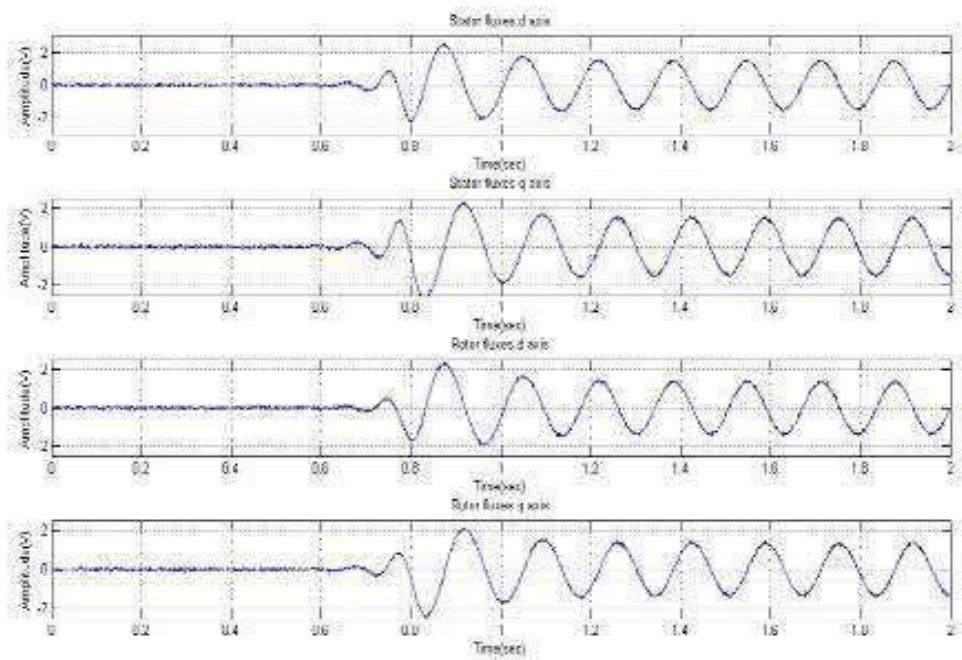

Fig. 8. Estimated stator and rotor d-q fixed axis fluxes using EKF

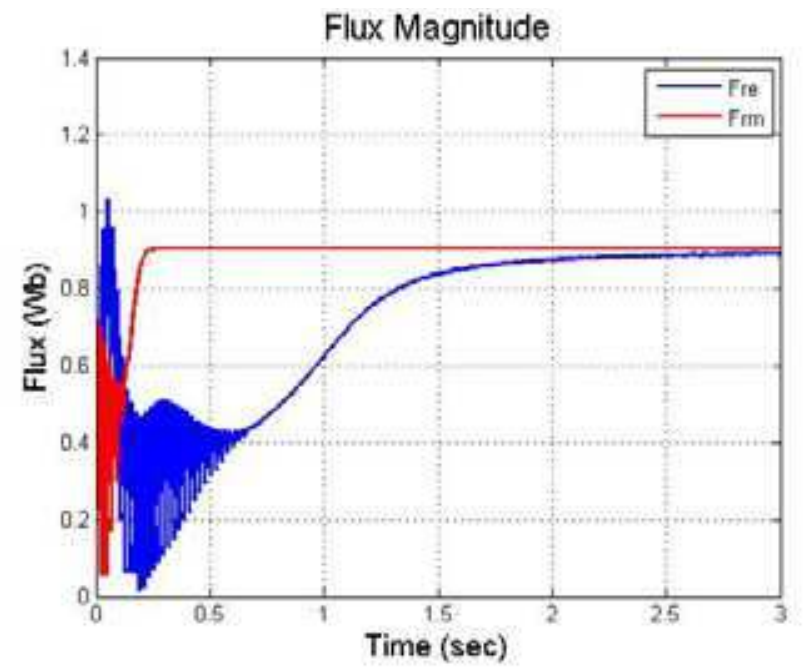

Fig. 9. Estimated rotor flux magnitude in $\mathrm{d}-\mathrm{q}$ rotating frame using EKF 
The estimated electromagnetic torque and the rotor speed of the induction drive can be observed in Fig. 11 and Fig. 12.

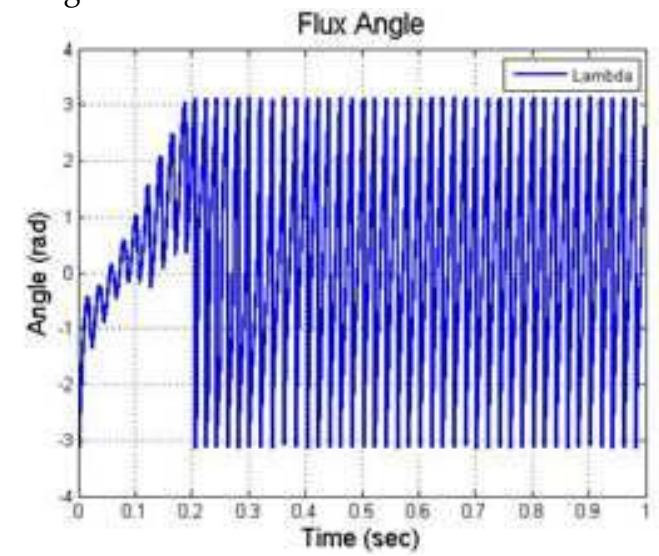

Fig. 10. Estimated rotor flux angle in d-q rotating frame using EKF

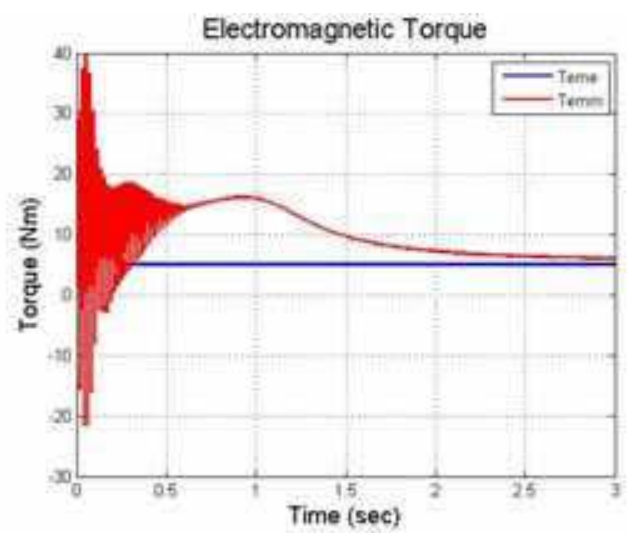

Fig. 11. Estimated electromagnetic torque using EKF

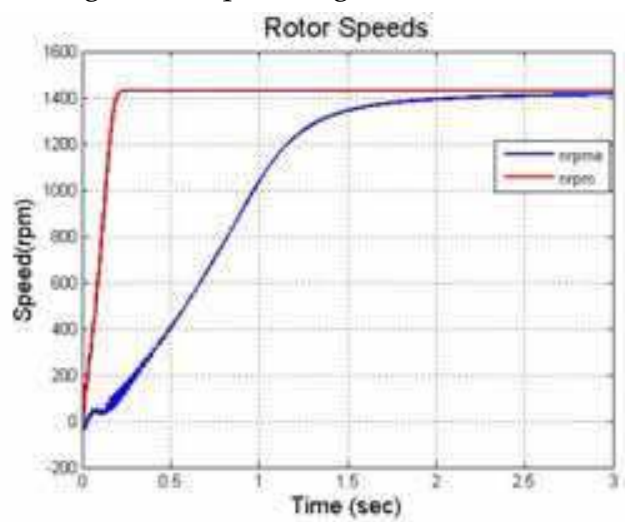

Fig. 12. Estimated rotor speed using EKF 


\section{$3.2 \mathrm{U}_{\mathrm{s}}-\mathrm{I}_{\mathrm{s}}$ estimator}

In order to integrate this estimator model in the control system of an induction machine, the stator voltages and currents are considered here as inputs, and the estimated outputs are the magnitude and the angle of the rotor flux and the electromagnetic torque.

This estimator is derived by direct synthesis from the machine state equations which are written in terms of the d-q axis components of the stator and rotor flux as state variables. This choice is justified by the fact that the system matrix is simpler than the d-q axis current state space model

The machine equations are derived from its general model where the speed of the rotational $\mathrm{d}$-q system of axes $\omega \lambda=0$, since a fixed reference frame is considered here.

The equations can be written in state space form. The outputs will be the stator and rotor currents.

$$
\begin{aligned}
x & =\left[\begin{array}{llll}
\psi_{s d} & \psi_{s q} & \psi_{r d} & \psi_{r q}
\end{array}\right]^{T} \\
u & =\left[\begin{array}{llll}
u_{s d} & u_{s q} & 0 & 0
\end{array}\right]^{T} \\
y & =\left[\begin{array}{llll}
i_{s d} & i_{s q} & i_{r d} & i_{r q}
\end{array}\right]^{T}
\end{aligned}
$$

The estimator mathematical model is based on the inverse model of the system:

$$
\begin{aligned}
& \frac{d \psi_{s d}}{d t}=\frac{L_{r}}{L_{m}}\left[u_{s d}-R_{s} i_{s d}-\sigma L_{s} \frac{d i_{s d}}{d t}\right] \\
& \frac{d \psi_{s q}}{d t}=\frac{L_{r}}{L_{m}}\left[u_{s q}-R_{s} i_{s q}-\sigma L_{s} \frac{d i_{s q}}{d t}\right]
\end{aligned}
$$

The Simulink model of the estimator can be observed in Fig. 13.

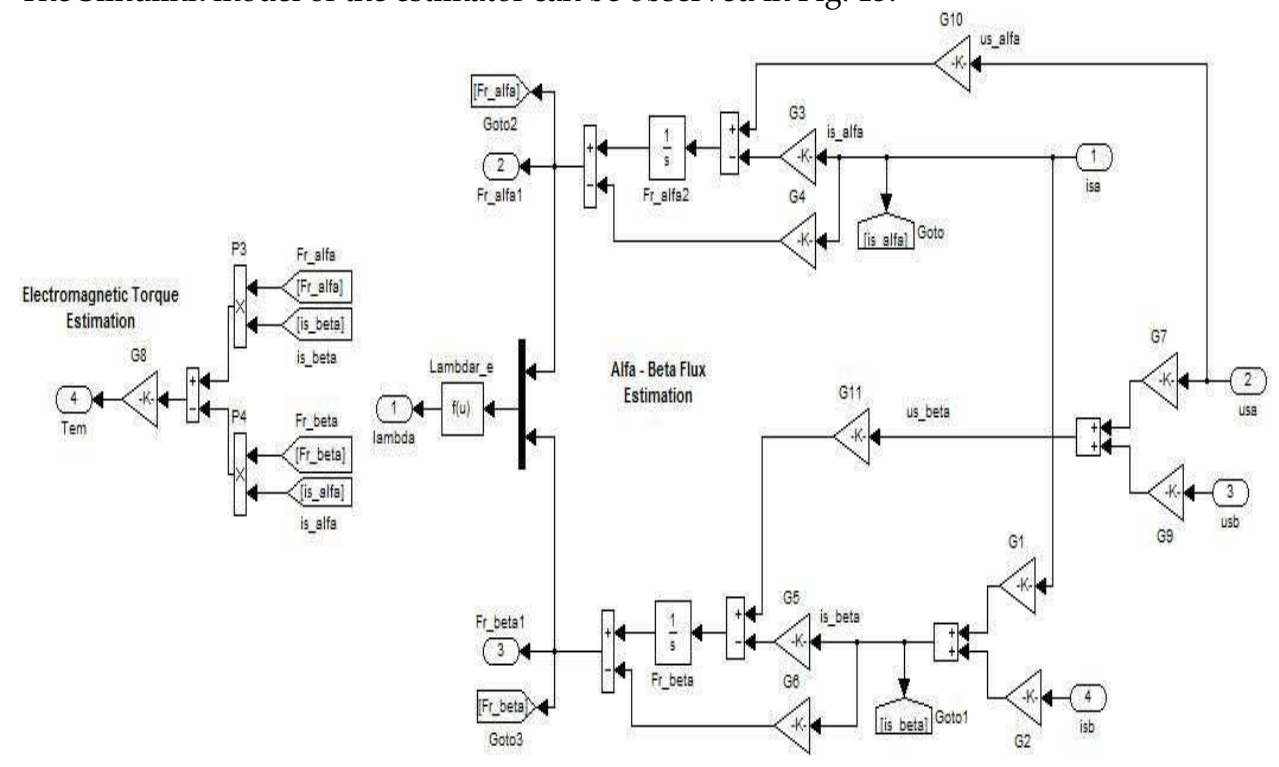

Fig. 13. Us-Is estimator Simulink model 
The electromagnetic torque is calculated like:

$$
T_{e}=\frac{3}{2} z_{p} \frac{L_{m}}{\sigma L_{s} L_{r}}\left(\psi_{s q} \psi_{r d}-\psi_{s d} \psi_{r q}\right)
$$

The rotor flux magnitude and angle can be written as:

$$
\begin{gathered}
\left|\underline{\psi_{r}}\right|=\sqrt{\psi_{r \alpha}{ }^{2}+\psi_{r \beta}{ }^{2}} \\
\lambda_{r}=\operatorname{arctg} \frac{\psi_{r \beta}}{\psi_{r \alpha}}
\end{gathered}
$$

The magnitude and the angle of the rotor flux estimates using Us-Is observer are shown in Fig. 14 and Fig. 15 and the electromagnetic torque estimation is seen in Fig. 16.

With the estimator Us-Is good output estimates were obtained when the machine was supplied with voltages in the range of rated value. At low speed range the acquisition of the voltages is difficult so the speed estimation is not accurate.

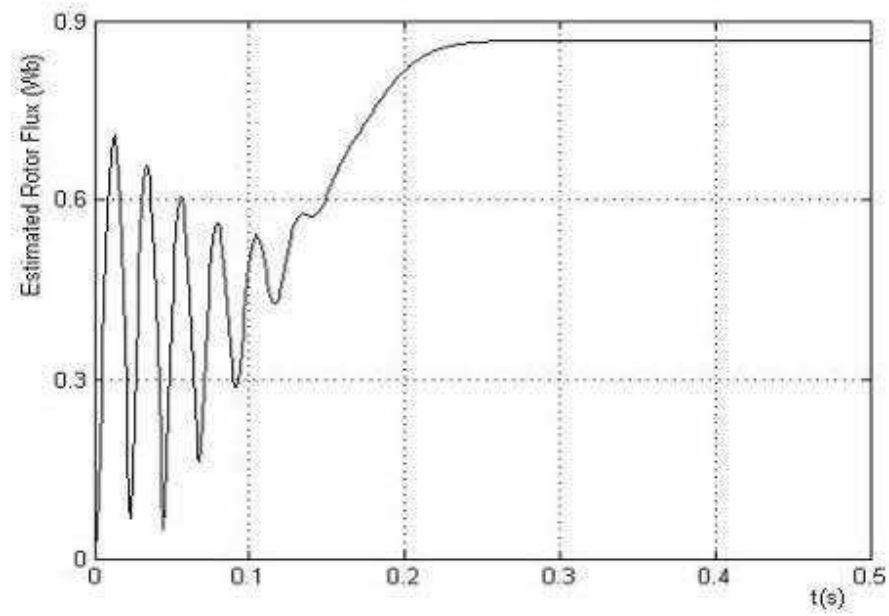

Fig. 14. Estimated rotor flux magnitude in d-q rotating frame using Us-Is estimator 


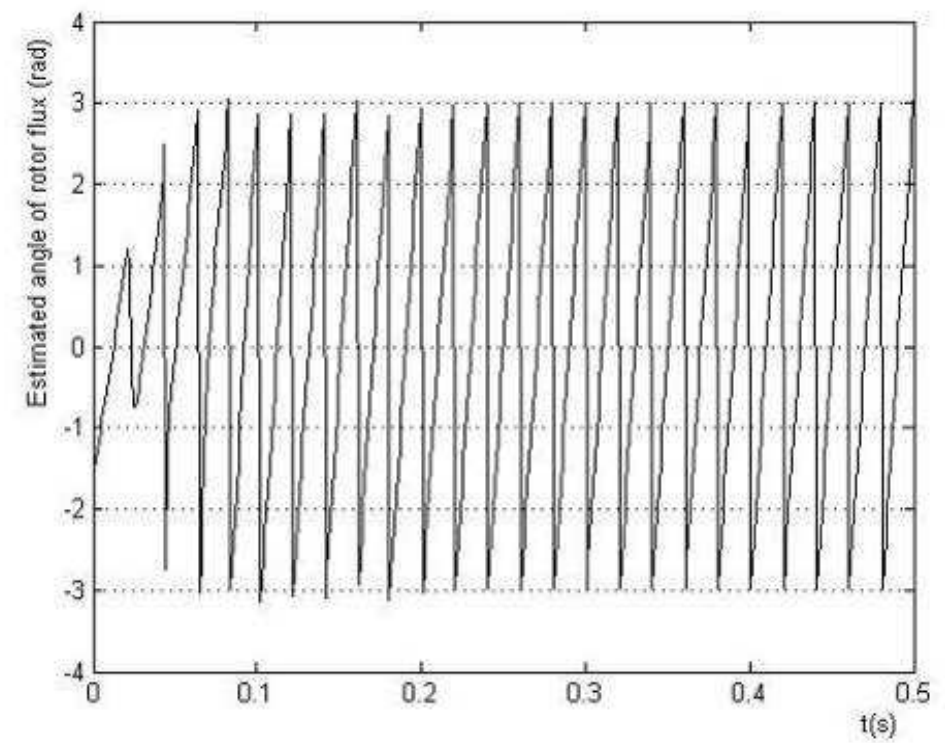

Fig. 15. Estimated rotor flux angle in d-q rotating frame using Us-Is estimator

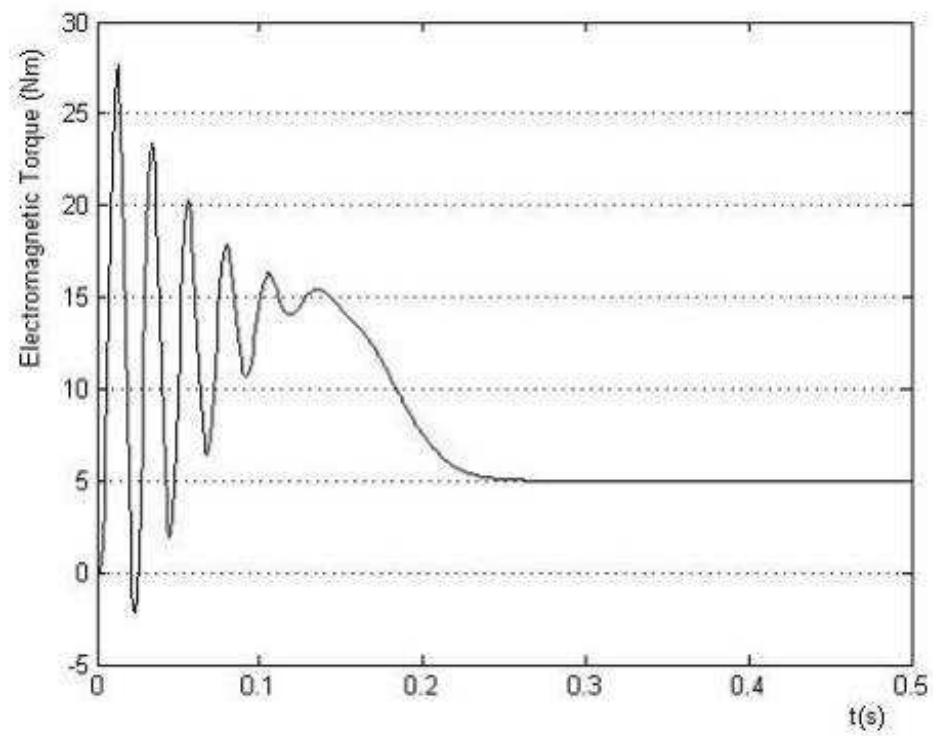

Fig. 16. Estimated electromagnetic torque using Us-Is estimator 


\subsection{Us-w estimator}

A rotor flux estimator which can operate in the range of low rotational speeds can be designed if one considers as measured inputs the stator voltages and the rotor angular velocity (Apostoaia \& Scutaru, 2006). This estimator is derived by direct synthesis from the machine state equations which are written in terms of the d-q axis components of the stator and rotor flux as state variables. The same assumptions were made as in the previous section for the estimator Us-Is.

We will denote the parameters used in the observer, as well as the estimated variables, with the same symbols like in the machine model but having the superscript " $\mathrm{e}$ " in addition. Thus, the system of equations of the flux observer is derived as follows:

$$
\begin{gathered}
\frac{d \psi_{s d}^{e}}{d t}=\frac{1}{T_{s}^{e}}\left[-\psi_{s d}^{e}+\omega_{\lambda} T_{s}^{e} \psi_{s q}^{e}+\frac{L_{m}^{e}}{L_{r}^{e}} \psi_{r d}^{e}+T_{s}^{e} u_{s d}\right] \\
\frac{d \psi_{s q}^{e}}{d t}=\frac{1}{T_{s}^{e}}\left[-\omega_{\lambda} T_{s}^{e} \psi_{s d}^{e}-\psi_{s q}^{e}+\frac{L_{m}^{e}}{L_{r}^{e}} \psi_{r q}^{e}+T_{s}^{e} u_{s q}\right] \\
\frac{d \psi_{r d}^{e}}{d t}=\frac{1}{T_{r}^{e}}\left[\frac{L_{m}^{e}}{L_{s}^{e}} \psi_{s d}^{e}-\psi_{r d}^{e}+T_{r}^{e}\left(\omega_{\lambda}-\omega\right) \psi_{r q}^{e}\right] \\
\frac{d \psi_{r q}^{e}}{d t}=\frac{1}{T_{r}^{e}}\left[\frac{L_{m}^{e}}{L_{s}^{e}} \psi_{s q}^{e}-T_{r}^{e}\left(\omega_{\lambda}-\omega\right) \psi_{r d}^{e}-\psi_{r q}^{e}\right]
\end{gathered}
$$

The dynamics of the flux estimator described by (36)-(39) is influenced by the time constants:

$$
T_{s}^{e}=\sigma^{e} \frac{L_{s}^{e}}{R_{s}^{e}}, \quad T_{r}^{e}=\sigma^{e} \frac{L_{r}^{e}}{R_{r}^{e}} .
$$

The electromagnetic torque is reconstructed in terms of the estimated state variables similarly to equation (33). The rotor flux magnitude and rotor flux angle are calculated like in (34) and (35).

The Simulink block diagram showing the Us- $\omega$ estimator can be seen in Fig. 17. 


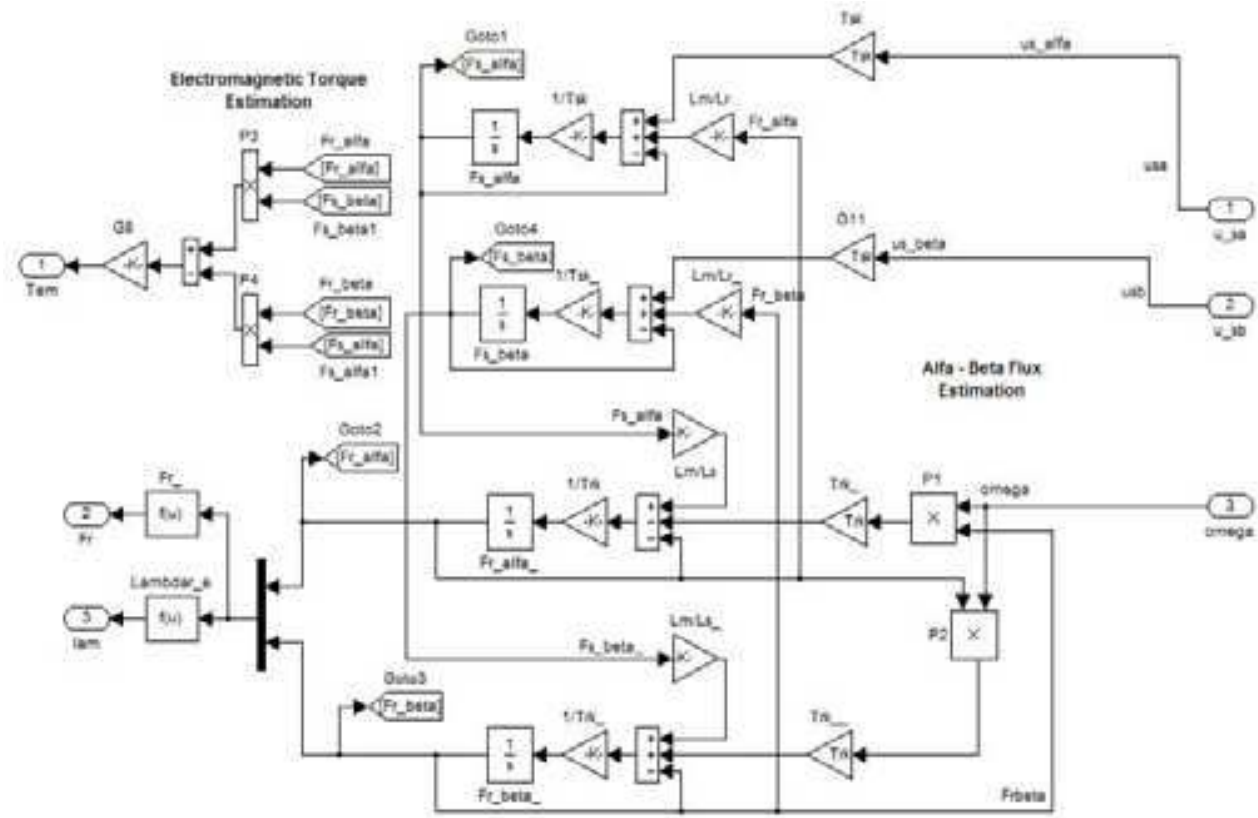

Fig. 17. Us- $\omega$ estimator Simulink model

In Fig. 18, Fig. 19, and Fig. 20, simulation results are shown for the Us- $\omega$ estimator, during a start up of the squirrel cage induction motor. A rated speed command under full torque load was used in the simulations.

The magnitude and the angle of the rotor flux estimates are shown in Fig. 18 and Fig. 19, and the electromagnetic torque estimation is seen in Fig. 20.

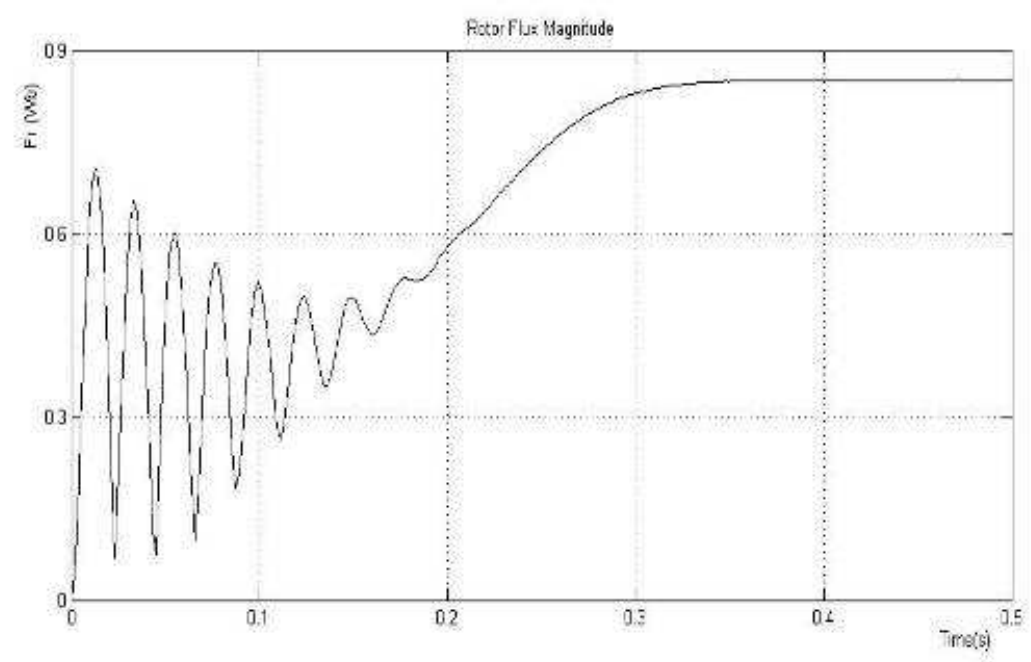

Fig. 18. Estimated rotor flux magnitude in d-q rotating frame using Us - $\omega$ estimator 


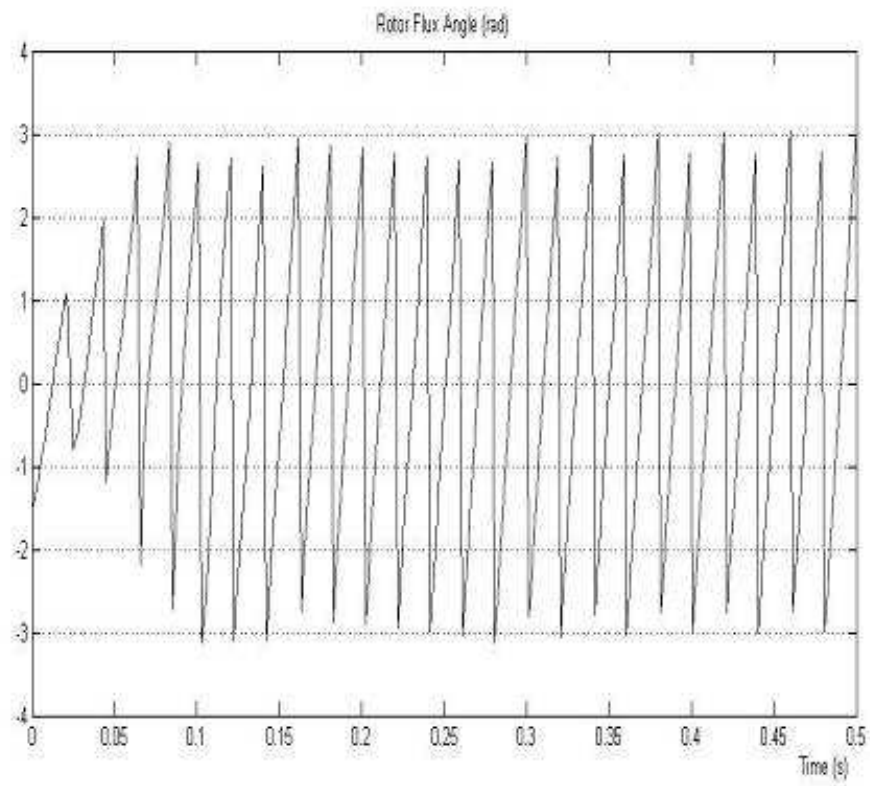

Fig. 19. Estimated rotor flux angle in d-q rotating frame using Us-- $\omega$ estimator

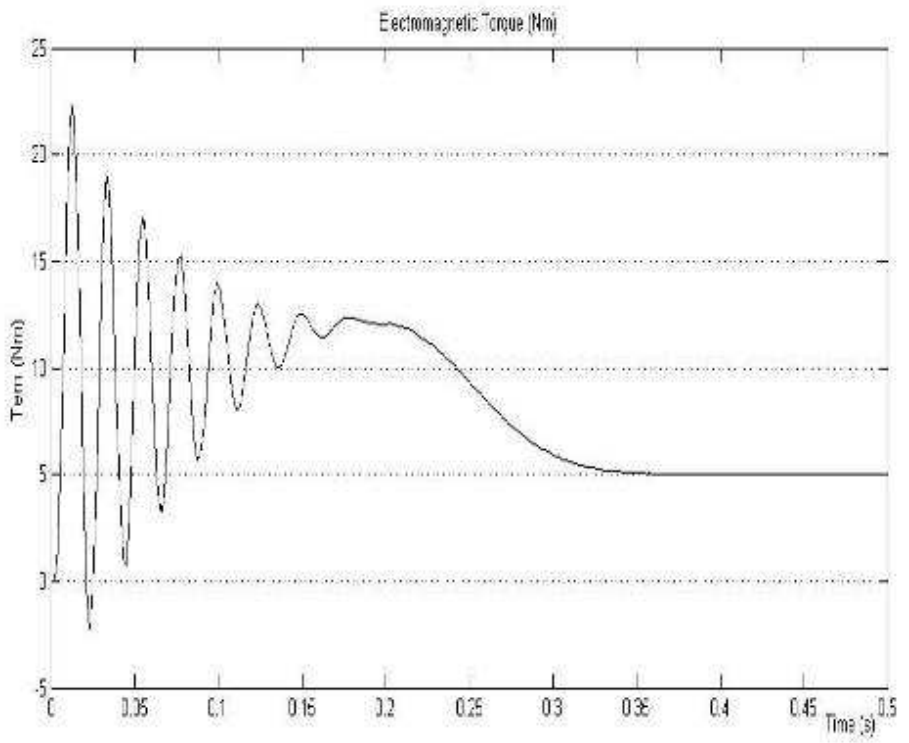

Fig. 20. Estimated electromagnetic torque using Us-- $\omega$ estimator 


\subsection{Neural network based speed estimator}

The inputs to the neural networks are the stator voltages and stator currents at time step $k$ and $k-1\left(u_{s d}, u_{s q}, i_{s d}, i_{s q}\right)$.The target is the rotor speed in revolutions per minute at time step $k$.

The network is a feedforward network with backpropagation algorithm. The training method is Levenberg-Marquardt (Caudill \& Butler, 1999).

The neural network has 2 layers with 30 neurons on the hidden layer, and with 'tansig' activation function, and one neuron on the output layer, with 'purelin' activation function. The derivative of the speed is estimated because the feedforward, backpropagation method is not appropriate of estimating integral components. The estimation of an integral component require some knowledge of the previous states and it would mean that the output of the network would need to be feed back as another input to the network. After the derivative component of the speed is estimated the simple integral method is used to extract the speed value, using 'cumsum' from MATLAB.

The derivative component of the speed can be seen in Fig. 21, while the estimated rotor speed after the integration can be found in Fig. 22.

As it can be seen from the below figures very good simulation results can be obtained using neural network for speed estimation, which can be used in combination with any other estimator in a sensorless vector control scheme or in sensor fusion control scheme(Simon, 2006).

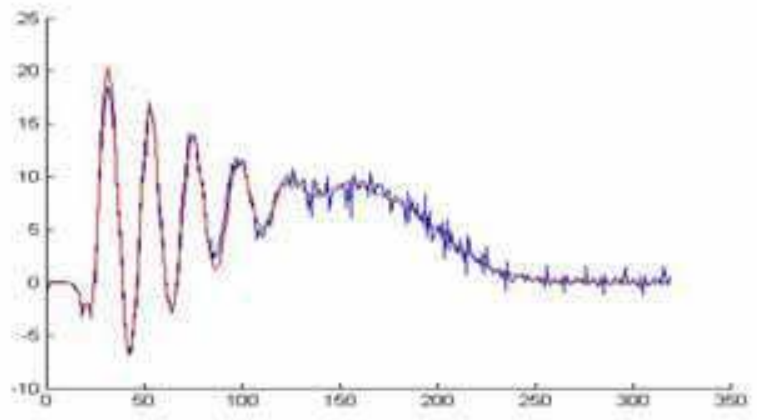

Fig. 21. The derivative component of the rotor speed using neural network

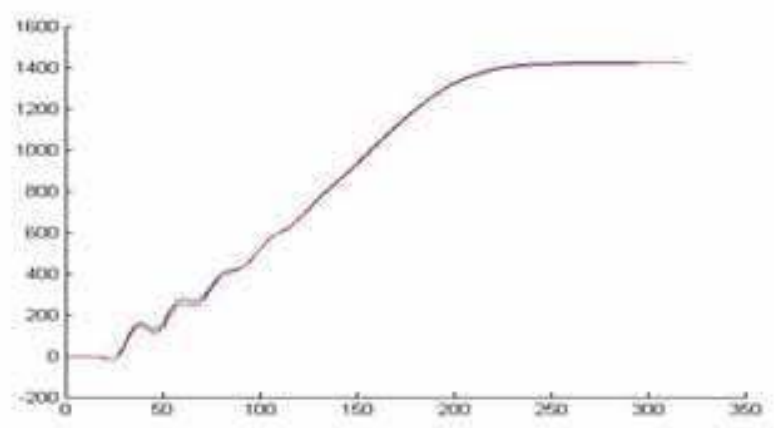

Fig. 22. The estimated rotor speed using neural network 


\section{Real-time simulation}

For the real-time implementation of the wind turbine system a dSPACE CLP1104 embedded system was used (Szekely, 2008).

For the real-time estimation of the rotor flux magnitude and angle, and of the electromagnetic torque, two stator current measurements and a speed measurement are required. Using the analog to digital (ADC 1 and 2) channels of the dSpace board, the two current measurement can be transferred to the computer together with the speed measured by the incremental encoder mounted on the induction generator shaft which is coupled with the wind turbine. The information from and to the computer is transferred through the dSpace board using the Digital I/O connector.

The Real-Time Simulink model of the estimator and measurement channels can be seen in Fig 23. In the feedback loop of the system two stator currents are measured together with the rotor speed. The currents are measured with LEM LA-NP 1752 currents transducers and the user has access to these measurements through BNC connectors. These signals are fed to the dSpace board, and from the board to the computer. The DS1104ADC_C5 and DS1104ADC_C6 blocks are used for the current measurements. The scaling factor for these measurement blocks is 1:20. For smoother measurement and better wave visualization a first order filter is also used.

The speed is measured using digital encoder and with the help of the blocks DS1104ENC_POS_C1 and DS1104ENC_SETUP can be used as an input for the observer. In order to receive the radian angle the DS1104ENC_POS_C1 block needs to be multiplied by $\frac{2 \pi}{\text { encoder }}$. In this experiment the encoder lines $=1000$. To obtain the desired speed the delta position scaled has to be divided by the sampling time $\omega=\frac{d \theta}{d t}=\frac{\Delta \theta}{T_{s}}$.

Using the mentioned measurements the rotor flux components can be estimated together with the rotor flux angle. Also the electromagnetic torque can be computed knowing the rotor flux components and having the two stator current measurements. The TAalfabeta2dq block transforms the rotor flux components from fixed reference frame to d-q rotating reference frame using the estimated rotor flux angle. This transformation is necessary for the field oriented vector control of the induction motor drive. Having the rotor flux components in rotating reference frame the rotor flux magnitude is calculated using equation (33). 


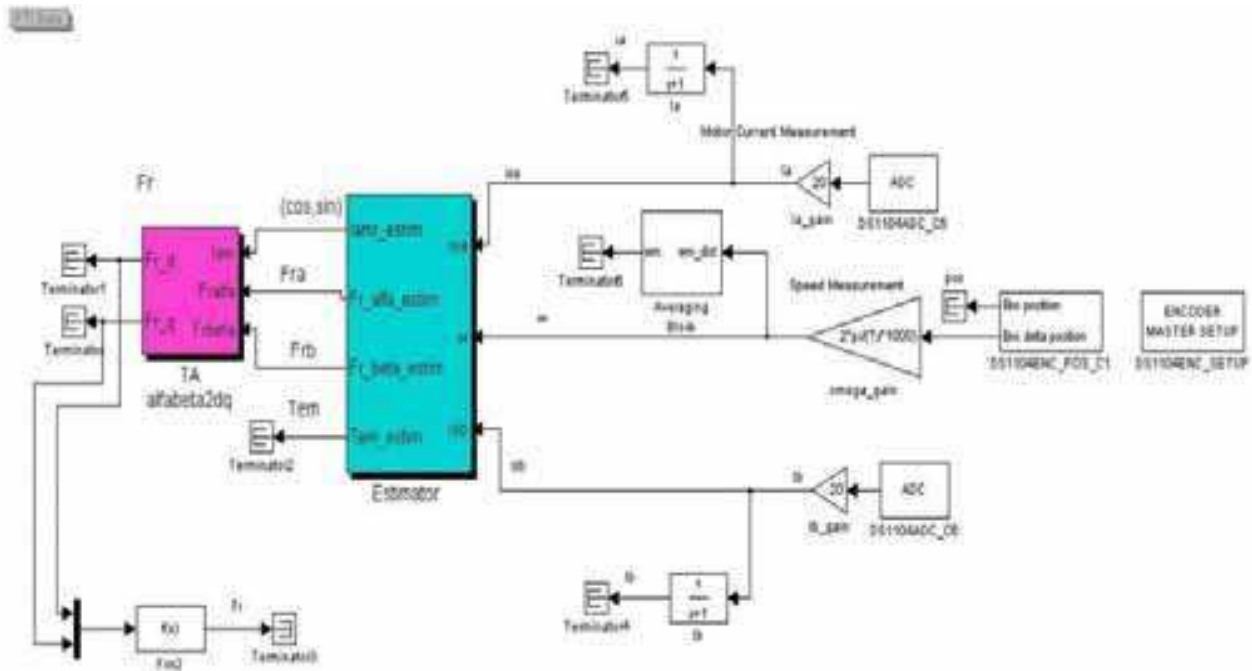

Fig 23. Real-time Simulink model of the measurement channels and the estimator

The real-time estimated values can be followed on the dSpace Control Desk as seen in Fig 24.

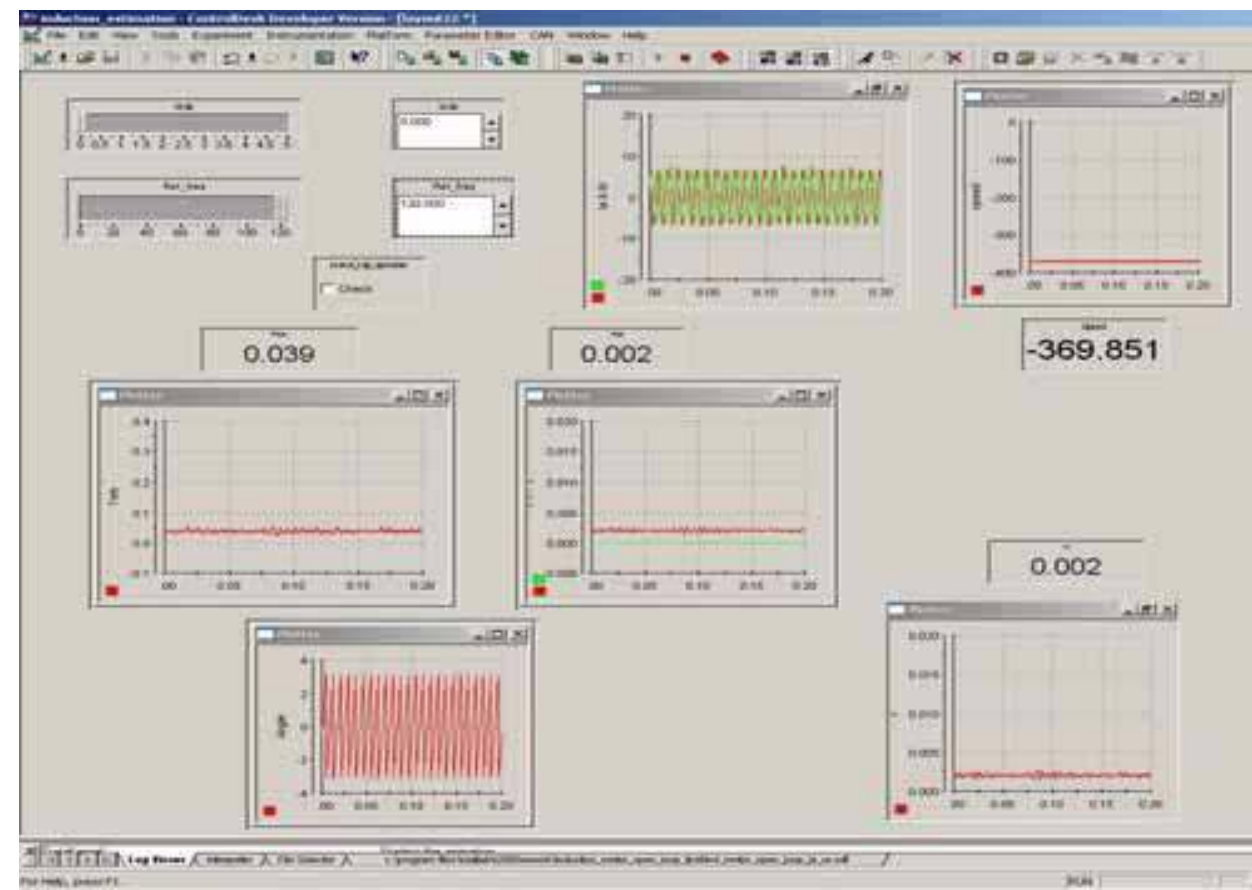

Fig 24. Real-time simulation results using dSpace Control Desk 


\section{Conclusions}

In this paper simulation of a wind energy conversion system based on the induction generator was carried out using Matlab-Simulink programming environment.

Good simulation results were obtained based on real data of the wind turbine and the induction generator to validate them.

Also, a stator and rotor flux estimator model based on EKF was developed to simulate the correct achievement of the field orientation. The developed EKF estimator can be successfully used in sensorless vector control systems.

The Us-Is estimator has a big advantage that it can be used in variable speed applications and a big advantage is the fact that the estimator equations are not containing the rotor resistance as parameter, which eliminates the problems caused by the temperature.

The estimator based on Us- $\omega$ has the advantage that is simple to implement but meanwhile is not taking into account any real system noise. Also uses open mathematical integration for the parameter estimation which is hard to implement in real applications.

The block diagrams were used to simulate the system in real time using an existing dSPACE DS 1104 control board. This board is based on a floating point DSP with high speed ADC converters which makes suitable for the cross compilation of the Simulink models into the dedicated platform.

Further steps of this research would involve the validation of the presented models and estimators for a real life small wind turbine. All the necessary software and hardware design is available through the use of the modern HIL dSpace cards.

\section{References}

L. Tamas \& Z. Szekely (2008): “Feedback Signals Estimation of an Induction Drive with Application to a Small Wind Turbine Generator, Automation Computers and Applied Mathematics, Volume 17, Number 4, 2008, p.642-651

Szekely, Z. (2008) “Extended Speed Control of an Induction Motor Drive utilizing Rotor Flux Orientation Technique in Real-Time", Masters Thesis, Purdue University Calumet, Hammond, Indiana, USA.

Scutaru, Gh. \& Apostoaia, C. (2004) “MATLAB-Simulink Model of a Stand- Alone Induction Generator", in Proc. OPTIM 2004, "Transilvania" University of Brasov, Romania, May 20-21, 2004, vol. II, pp.155-162

Apostoaia, C. \& Scutaru, Gh. (2006) "A Dynamic Model of a Wind Turbine System", in Proceedings OPTIM 2006, "Transilvania" University of Brasov, Romania, May 1819, 2006, vol. II, pp.261-266

A. Kelemen, M. Imecs (1991): Vector Control of AC Drives, Volume 1; Vector Control of Induction Machine Drives, OMIKK-Publisher, Budapest, Hungary

Kalman, R.E. (1960): A new approach to linear filtering and prediction problems. Transactions of the ASME-Journal of Basic Engineering, Vol. 82

Simon, D. (2006): Optimal State Estimation. v. 1., Willey Interscience.

Caudill, M. \& C. Butler (1992) Understanding Neural Networks: Computer Explorations, Vols. 1 and 2, Cambridge, MA: The MIT Press. 


\section{Renewable Energy}

Edited by $\mathrm{T} \mathrm{J}$ Hammons

ISBN 978-953-7619-52-7

Hard cover, 580 pages

Publisher InTech

Published online 01, December, 2009

Published in print edition December, 2009

Renewable Energy is energy generated from natural resources-such as sunlight, wind, rain, tides and geothermal heat-which are naturally replenished. In 2008 , about $18 \%$ of global final energy consumption came from renewables, with $13 \%$ coming from traditional biomass, such as wood burning. Hydroelectricity was the next largest renewable source, providing $3 \%$ (15\% of global electricity generation), followed by solar hot water/heating, which contributed with 1.3\%. Modern technologies, such as geothermal energy, wind power, solar power, and ocean energy together provided some $0.8 \%$ of final energy consumption. The book provides a forum for dissemination and exchange of up-to-date scientific information on theoretical, generic and applied areas of knowledge. The topics deal with new devices and circuits for energy systems, photovoltaic and solar thermal, wind energy systems, tidal and wave energy, fuel cell systems, bio energy and geo-energy, sustainable energy resources and systems, energy storage systems, energy market management and economics, off-grid isolated energy systems, energy in transportation systems, energy resources for portable electronics, intelligent energy power transmission, distribution and inter-connectors, energy efficient utilization, environmental issues, energy harvesting, nanotechnology in energy, policy issues on renewable energy, building design, power electronics in energy conversion, new materials for energy resources, and RF and magnetic field energy devices.

\section{How to reference}

In order to correctly reference this scholarly work, feel free to copy and paste the following:

Levente Tamas and Zoltan Szekely (2009). Modeling and Simulation of an Induction Drive with Application to a Small Wind Turbine Generator, Renewable Energy, T J Hammons (Ed.), ISBN: 978-953-7619-52-7, InTech, Available from: http://www.intechopen.com/books/renewable-energy/modeling-and-simulation-of-an-inductiondrive-with-application-to-a-small-wind-turbine-generator

\section{INTECH}

open science | open minds

\section{InTech Europe}

University Campus STeP Ri

Slavka Krautzeka 83/A

51000 Rijeka, Croatia

Phone: +385 (51) 770447

Fax: +385 (51) 686166

www.intechopen.com

\section{InTech China}

Unit 405, Office Block, Hotel Equatorial Shanghai

No.65, Yan An Road (West), Shanghai, 200040, China 中国上海市延安西路65号上海国际贵都大饭店办公楼405单元

Phone: +86-21-62489820

Fax: $+86-21-62489821$ 
(C) 2009 The Author(s). Licensee IntechOpen. This chapter is distributed under the terms of the Creative Commons Attribution-NonCommercial-ShareAlike-3.0 License, which permits use, distribution and reproduction for non-commercial purposes, provided the original is properly cited and derivative works building on this content are distributed under the same license. 